\title{
High prevalence of human cytomegalovirus in carotid atherosclerotic plaques obtained from Russian patients undergoing carotid endarterectomy
}

Koon-Chu Yaiw ${ }^{1}$, Olga Ovchinnikova ${ }^{1,2+}$, Chato Taher $^{1 \dagger}$, Abdul-Aleem Mohammad $^{1 \dagger}$, Belghis Davoudi ${ }^{1}$, Eugene Shlyakhto ${ }^{2}$, Oxana Rotar ${ }^{2}$, Alexandra Konradi ${ }^{2}$, Vanessa Wilhelmi ${ }^{1}$, Afsar Rahbar ${ }^{1}$, Lynn Butler ${ }^{1}$, Alice Assinger ${ }^{1}$ and Cecilia Söderberg-Nauclér ${ }^{1 *}$

\begin{abstract}
Background: Human cytomegalovirus (HCMV) infection is associated with cardiovascular disease (CVD) but the role of this virus in CVD progression remains unclear. We aimed to examine the HCMV serostatus in Russian patients $(n=90)$ who had undergone carotid endarterectomy (CEA) and controls $(n=82)$ as well as to determine the prevalence of HCMV immediate early (IE) and late (LA) antigens in carotid atherosclerotic plaques obtained from 89 patients. In addition, we sought to determine whether HCMV infection was associated with inflammatory activity in the plaque by quantifying infiltrating CD3 and CD68 positive cells and 5-LO immunoreactivity.

Methods: HCMV serology was assessed with ELISA and immunohistochemistry staining was performed to detect HCMV antigens, CD3, CD68 and 5-LO reactivity. The Fisher's exact test was used to compare i) seroprevalence of HCMV IgG between patients and controls and ii) HCMV-positive or -negative to that of CD3, CD68 and 5-LO immunoreactive cells in plaque samples. The student- $t$ test was performed to connote the significance level of mean optical density between patients and controls.

Results: The seroprevalence for HCMV IgG was high in both patients and controls (99\% and 98\%, respectively). Controls had significantly higher lgG titers for HCMV compared with patients $(p=0.0148)$. Strikingly, we found a high prevalence of HCMV antigens in atherosclerotic plaques; 57/89 (64\%) and 47/87 (54\%) were HCMV IE and LA positive, respectively. Most plaques had rather low HCMV reactivity with distinct areas of HCMV-positive cells mainly detected in shoulder regions of the plaques, but also in the area adjacent to the necrotic core and fibrous cap. In plaques, the cellular targets for HCMV infection appeared to be mainly macrophages/foam cells and smooth muscle cells. HCMV-positive plaques trended to be associated with increased numbers of CD68 positive macrophages and CD3 positive T cells, while 5-LO reactivity was high in both HCMV-positive and HCMV-negative plaques.
\end{abstract}

Conclusions: In Russian patients undergoing CEA, HCMV proteins are abundantly expressed in carotid plaques and may contribute to the inflammatory response in plaques via enhanced infiltration of CD68 and CD3 cells.

Keywords: Cytomegalovirus, Serostatus, Carotid atherosclerotic plaque, Viral antigens in plaques, Inflammatory markers

\footnotetext{
* Correspondence: Cecilia.Naucler@ki.se

${ }^{\dagger}$ Equal contributors

'Department of Medicine, Center for Molecular Medicine, CMM L8:03,

Karolinska Institutet, Solna, Stockholm SE-171 76, Sweden

Full list of author information is available at the end of the article
} 


\section{Background}

Human cytomegalovirus (HCMV) is a DNA virus that belongs to the family Herpesviridae [1]. It is a ubiquitous but species-specific virus that remains latent in host cells upon primary infection. Its seroprevalence varies from 40-100\% depending on age, socioeconomic status and geographical locations [2]. HCMV is known as an opportunistic infection in immunocompromised individuals and it is the main etiological agent responsible for congenital viral diseases [1]. Accumulating evidence also supports a plausible role of microbial infection in the pathogenesis of cardiovascular disease (CVD) [3]. For example, many studies show the presence and probable active role of microbes such as Chlamydia pneumonia, Helicobacter pylori and certain periodontal pathogens or viruses, such as herpes simplex virus and HCMV in the pathogenesis of CVD [3,4]. Among these, HCMV and Chlamydia pneumonia provide the strongest evidence of a link to CVD through seroepidemiological, clinical and experimental models [5-7].

HCMV has been proposed to influence various cardiovascular disease processes $[3,8,9]$. HCMV nucleic acids and/or antigens have been detected in atherosclerotic plaques [10,11]. Furthermore, elevated antibody levels against HCMV are positively correlated with atherosclerosis [12], coronary artery disease [13] and more recently, with CVD mortality [5,14-16]. In a mouse model, Cheng et al. provided evidence that murine CMV possibly results in enhanced arterial blood pressure through increased angiotensin II [17]. Interestingly, patients with essential hypertension have higher HCMV-specific microRNA levels in plasma [18]. However, some studies have also failed to detect the presence of HCMV in atherosclerotic plaques or show any association between this virus and CVD $[19,20]$. Hence, the role of HCMV in CVD remains controversial.

Inflammation is a well-established atherogenesis promoter that increases CVD risk and contributes to plaque rupture $[21,22]$. Among known proinflammatory mediators in CVD, leukotrienes are potent chemotactic molecules, which attract leukocytes and induce vascular permeability and smooth muscle cell contraction. 5lipoxygenase (5-LO) catalyzes the first steps in the conversion of arachidonic acid to leukotrienes, and is implied in the pathogenesis of atherosclerosis, restenosis and plaque instability [23]. In atherosclerotic plaques, the expression of 5-LO is mainly restricted to granulocytes, monocytes/macrophages, foam cells, dendritic cells, B cells and mast cells but not T cells [24]. HCMV induces expression of both 5-LO mRNA and proteins as well as leukotriene B4 (LTB4) production in infected vascular smooth muscle cells [25], which otherwise are unable to produce LTB4. HCMV could thereby contribute to local inflammation in the vascular wall and drive
CVD progression. Inflammation is also a driving force for reactivation of latent $\mathrm{HCMV}[26,27]$, and replication of this virus in macrophages [28]. We therefore hypothesize that HCMV positivity is associated with inflammation. In this study, we aimed to determine the HCMV serostatus in Russian patients who underwent carotid endarterectomy (CEA) and in controls. We also sought to examine the presence of HCMV immediate early (IE) and late (LA) antigens in carotid atherosclerotic plaques and to search for an association between HCMV positivity and enhanced presence of inflammatory markers, i.e.: 5-LO, CD3 and CD68 in CEA biopsy specimens.

\section{Materials and methods}

\section{Specimens}

Both sera $(\mathrm{n}=90)$ and human atherosclerotic plaque tissue samples $(n=89)$ were obtained from Russian patients with CEA that were stored in St. Petersburg Investigation of Carotid Endarterectomies (SPICE) Biobank (Table 1). The Ethical Committee of Palvov State Medical University of St. Petersburg approved the studies. Pieces of plaques were embedded in Optimal Cutting Temperature compound (Sakura Finetek, the Netherlands) and frozen for immunohistochemistry or nucleic acid analysis. The control sera were from 83 control individuals and the study was approved by the Institutional Review Board on cardiology and endocrinology from the Almazov Federal Heart, Blood and Endocrinology Centre, St. Petersburg. Among these controls, 67 of them had $\leq 1.2 \mathrm{~mm}$ carotid intimamedia thickness and 16 of them had low degree of atherosclerosis whom at present had no symptoms.

Table 1 Patient demographics and characteristics

\begin{tabular}{|c|c|}
\hline Clinical parameters & Values \\
\hline Male : Female (n) & 72: 18 \\
\hline Age (mean $\pm S D)$ & $62.0 \pm 8.2$ \\
\hline Symptoms, yes (\%) & 38.6 (32 of $n * 83$ ) \\
\hline Ipsilateral carotid stenosis (\%) & $78.0 \pm 10.3\left(\right.$ of $\left.n^{*} 77\right)$ \\
\hline \multicolumn{2}{|l|}{ Risk factors: } \\
\hline Smoking, yes (\%) & 48.1 (37 of $n^{*} 77$ ) \\
\hline $\mathrm{BMI}\left(\mathrm{kg} / \mathrm{m}^{2}\right)$ & $26.7 \pm 4.7\left(\right.$ of $\left.n^{*} 78\right)$ \\
\hline Diabetes mellitus type 2, yes (\%) & $26.3(21$ of $n * 80)$ \\
\hline Hypertension, yes (\%) & $96.3(78$ of $n * 81)$ \\
\hline Total cholesterol (mmol/L) & $5.6 \pm 1.3($ of $n * 84)$ \\
\hline \multicolumn{2}{|l|}{ Treatment: } \\
\hline Statins (\%) & $33.3 \%(27$ of $n * 81)$ \\
\hline Antiplatelet drugs (\%) & $82.5(66$ of $n * 80)$ \\
\hline Antihypertensive drugs (\%) & 73.8 (59 of $n^{*} 80$ ) \\
\hline
\end{tabular}

$B M I$ body mass index, values are mean \pm SD if not indicated otherwise, $n^{*}$ number of patients with available variant; Symptoms refer to transient ischemic attack, ischemic stroke or retinal ischemia. 


\section{Enzyme-linked immunosorbent assay (ELISA)}

HCMV IgM titers were determined by ELISA (Enzygnost anti-CMV/IgM, Siemens, Germany) and IgG by an inhouse anti-CMV/IgG ELISA assay, Karolinska University Hospital, Sweden). This assay is used for routine clinical diagnostics at the accredited Clinical Virology Laboratory at the Karolinska University Hospital. We obtained comparable results by using this method and two commercial kits (Afsar Rahbar, personal communication). The antiCMV/IgM ELISA was assayed in duplicates according to the manual's instruction. For the anti-CMV/IgG ELISA, an in-house prepared 96-well plate coated with $\mathrm{CMV} /$ control antigens was washed 3 times with washing buffer $(0.9 \%$ $\mathrm{NaCl} / 0.05 \%$ Tween 20), incubated at $37^{\circ} \mathrm{C}, 60$ mins with plasma (1:500), thereafter washed 4 times and incubated with polyclonal rabbit anti-human IgG conjugated to horseradish peroxidase (Dako, Denmark), 1:5000 in 1\% BSA/PBS for 5 mins on a shaker at RT and thereafter for 60 mins at $37^{\circ} \mathrm{C}$. After 4 washings, reactivity was detected using o-phenylenediamine. The reaction was stopped with $2.5 \mathrm{M}$ sulphuric acid (Merck, Germany). The O.D. was read at $492 \mathrm{~nm}$. The cut-off value for positivity was an O.D. > 0.2.

\section{Immunohistochemistry (IHC)}

IHC was performed with $8-10 \mu \mathrm{m}$ thick acetone/methanol-fixed cryosections using ImmPRESS detection system. After endogenous peroxidase quenching, sections were sequentially incubated with protein block, Fc receptor blocker, followed by normal horse serum, all for 20 mins at RT. Primary antibodies, mouse anti-HCMV immediate early (IE, Millipore, MAB810R, clone 8B1.2, 1:500), mouse anti-HCMV late proteins (Millipore, MAB8127, clone 1G5.2, 1:500), mouse anti-human CD68 (Dako, M0876, clone PG-M1,1:200), mouse antihuman CD3 (Dako, M7254, clone F7.2.38, 1:100) and rabbit anti-5-LO (Abcam, ab39347, 1:400) were applied and incubated overnight at $4{ }^{\circ} \mathrm{C}$. Negative controls were prepared by omitting the primary antibody (TBS only) or with isotype controls. HCMV VR1814-infected endothelial cells served as positive controls. Immunoreactivity was detected with diaminobenzidine (DAB) and counterstained with hematoxylin before microscope viewing. The staining was graded according to the estimated percentage of positive cells with grade I denoting $<25 \%$; grade II, $25-50 \%$; grade III, $51-75 \%$ and grade IV, $>75 \%$ as previously described [29].

\section{TaqMan PCR}

Tissue plaques samples were cut into small pieces, incubated with Proteinase $\mathrm{K}$ overnight and DNA was extracted using DNeasy Blood \& Tissue kit (Qiagen). The primers and probe sequences used for the HCMV IE DNA detection were as previously described [30]. The TaqMan reaction was performed with fast master mix using ABI Prism 7900HT with the default thermocycling profile using $50 \mathrm{ng}$ as template in triplicates along with positive and non-template controls. We used HCMVinfected fibroblast cells as a positive control and a nontemplate control of water as a negative control. In addition, we also utilized the first WHO International Standard for HCMV developed by NIBSC (code 09/162) to make a standard curve in order to calculate the viral copy number. In brief, the assigned $5 \times 10^{6} \mathrm{IU}$ of HCMV in $1 \mathrm{ml}$ of nuclease-free water was subjected to DNA extraction using QIAamp MinElute Virus Spin Kits (Qiagen) and the DNA was eluted with $100 \mu \mathrm{l}$ of nuclease-free water. A standard curve was then generated using a serial of tenfold dilution with two microliter of each dilution was used in a total volume of $10 \mu \mathrm{l}$ reaction.

\section{Statistical analysis}

All statistical analysis was performed using GraphPad Prism 5 software. The Fisher's exact test was used to compare i) seroprevalence of HCMV IgG between patients and controls and ii) HCMV-positive or -negative to that of CD3, CD68 and 5-LO immunoreactive cells in plaque samples. The student- $t$ test was performed to connote the significance level of mean optical density between patients and controls. A p value $<0.05$ was considered statistically significant.

\section{Results}

\section{HCMV IgG titers are lower among CEA patients than controls}

Table 1 shows all the available patient demographics and characteristics for 90 sera from CEA patients that were examined in our study. The ratio of males to females was 4:1 (i.e. males, $\mathrm{n}=72$ and females, $\mathrm{n}=18$ ) and the mean age was $62.0 \pm 8.2($ mean $\pm \mathrm{SD}$ ) for males and $65.8 \pm 8.6$ for females. 89 of 90 (99\%) sera from CEA patients were positive for HCMV IgG. One (1\%) was positive for IgM and three (3\%) were equivocal (Figure 1A). From controls, we obtained 83 serum samples; HCMV IgG and IgM titres were determined in 82 samples by ELISA (1 sample was insufficient in quantity for the assay). Females constituted the major gender $(n=56)$ among controls (ratio male to female approximately $1: 2$ ) with mean age of $56.8 \pm 9.5$ for females compared to $52.2 \pm 14.5$ for males. The controls showed similar patterns of HCMV IgG seroprevalence; 80/82 (98\%) were HCMV IgG positive (Figure 1B), none was IgM positive and 2/74 (3\%) were equivocal for IgM (Figure 1B). Thus, there was no significant difference in HCMV IgG positivity between patients with CEA and controls $(p=0.6059)$. However, we observed that controls had a significantly higher O.D. value for HCMV IgG compared to patients $(1.95 \pm 0.57$ and $1.71 \pm 0.68$, respectively; $\mathrm{p}=0.0148$, Figure $1 \mathrm{C}$ ). Removal of 16 controls with low degree of atherosclerosis resulted in the same conclusion 


\section{A}

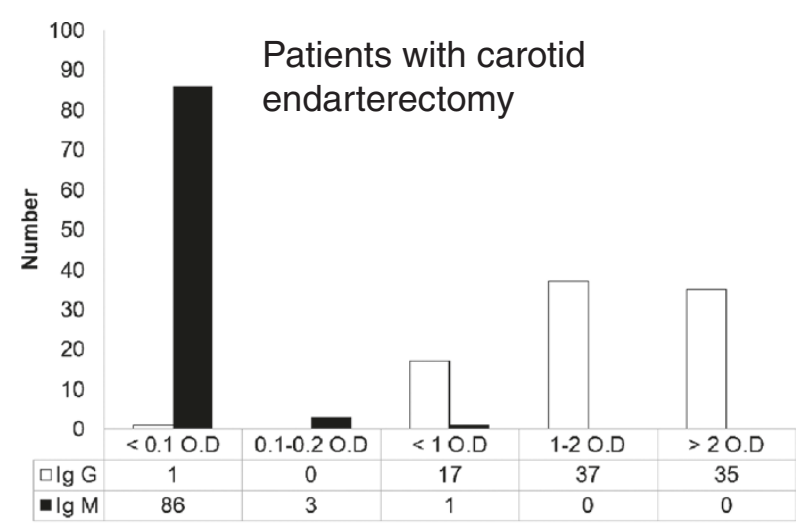

B
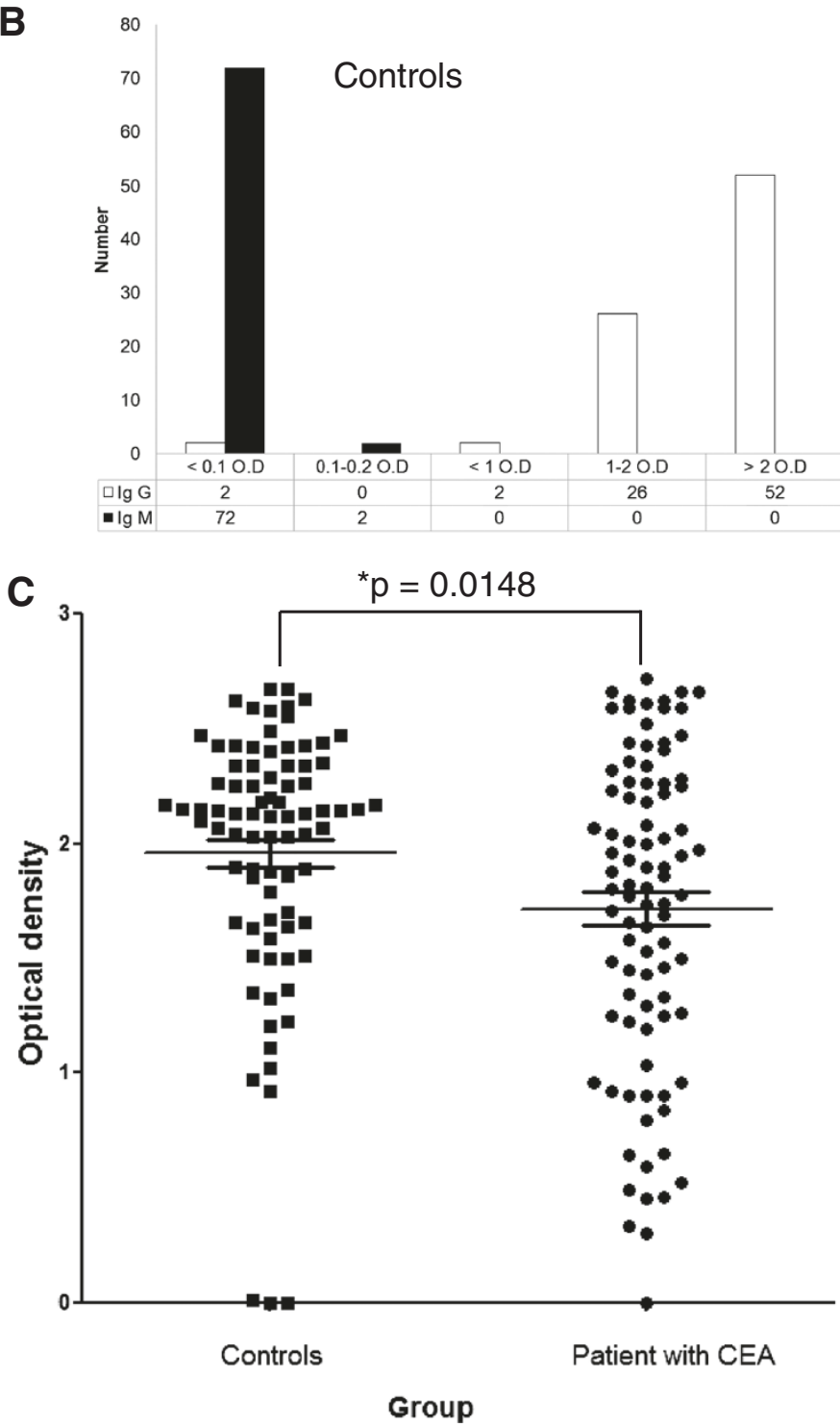

Figure 1 Serological analysis of human cytomegalovirus (HCMV) antibodies in Russian patients with carotid endarterectomy (CEA) and controls. (A) and (B) Bar graphs show seroprevalence of IgG and IgM antibodies against HCMV in patient with CEA or controls, respectively. (C) Scatter plot shows optical density of IgG between patients with CEA and controls. Carotid endarterectomy, CEA; Optical density, O.D.; ${ }^{*} \mathrm{p}<0.05$. 


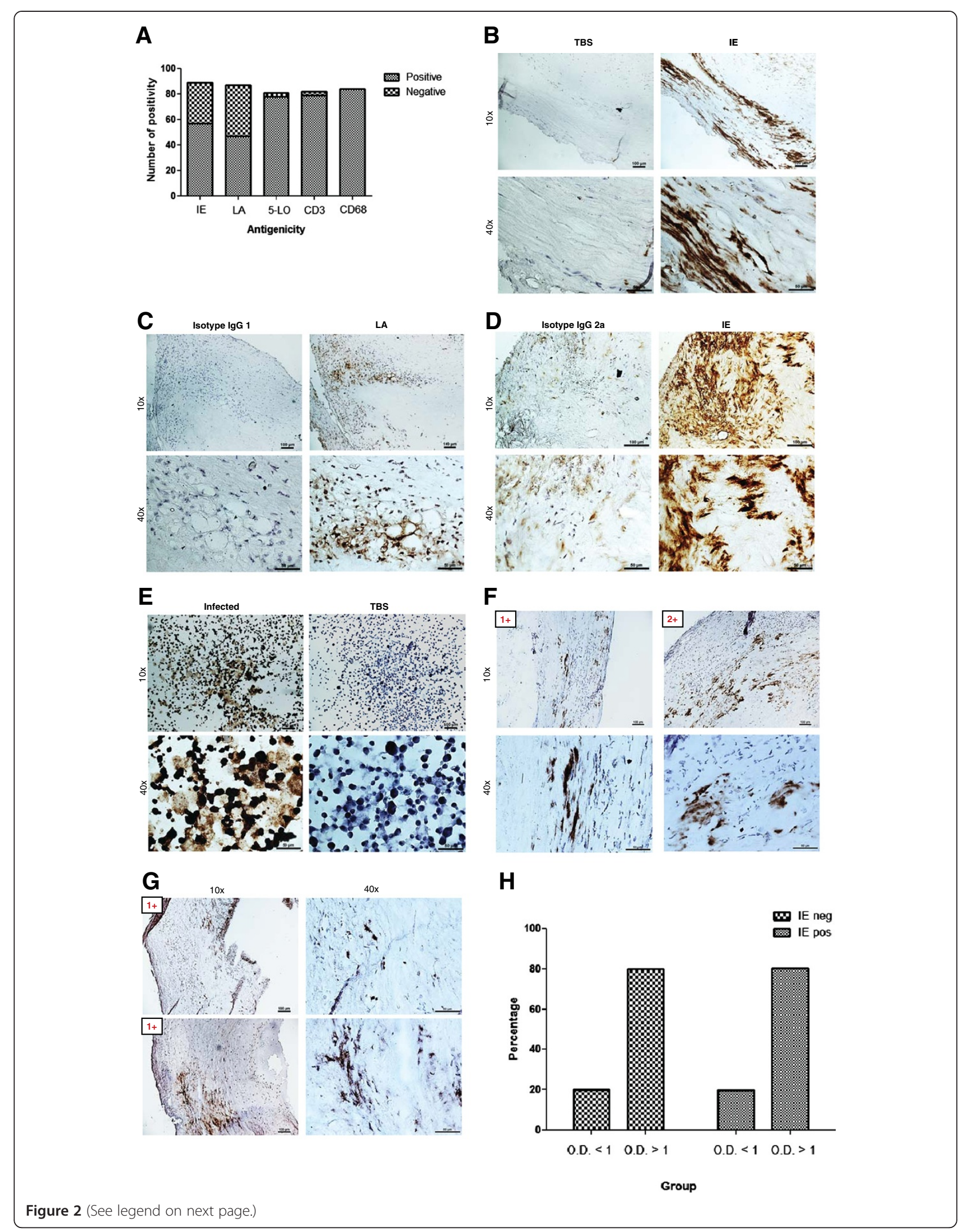


(See figure on previous page.)

Figure 2 Immunoreactivity and grading of human cytomegalovirus (HCMV) antigens and inflammatory markers in human carotid atherosclerotic plaques as assayed by immunohistochemistry (IHC) staining. (A) Summary of IHC results on viral immediate early (IE), late (LA), 5-LO, CD3 and CD68 in plaques. (B-E) Panel of controls consist of omitting primary antibody (or Tris-buffered saline, TBS only) instead of IE (B), isotype control for LA (C), isotype control for IE (D), and virus-infected endothelial cells (E). (F-G) Immunoreactivity and grading of IE (F) or LA (G) in plaques. (H) Association between HCMV IgG antibodies and its IE antigens burden. Positivity was revealed by diaminobenzidine (DAB), brown products; Optical density, O.D.

either for HCMV IgG positivity or mean O.D. between patient with CEA and controls.

\section{HCMV IE and LA are frequently present in atherosclerotic} plaques

We examined 89 frozen tissue samples obtained from CEA patients for HCMV IE and 87 for HCMV LA. Strikingly, $57 / 89$ (64\%) and 47/87 (54\%) were positive for HCMV IE and LA, respectively (Figure 2A). Minimal or no HCMV immunoreactivity was detected in sections incubated with TBS (i.e. omitting primary antibody) (Figure 2B) or using isotype control antibodies (IgG1 and IgG2a) (Figure 2C-2D, respectively). Endothelial cells infected in vitro were positive for HCMV IE and LA (Figure 2E).

To confirm the presence of HCMV nucleic acids in plaques, we randomly selected 9 samples from HCMV IHC-positive and 9 samples of IHC-negative tissue plaques, isolated DNA and performed TaqMan PCR analysis for HCMV. We detected 4/9 (44\%) samples positive for IE DNA, while none of nine IHC-negative plaques was positive for HCMV IE (Table 2). We used HCMV- infected fibroblast cells as positive control for the PCR assay, which was always positive, with an average threshold cycle $=15.0 \pm 0.2$ (equivalent to $7.7 \times 10^{9} \mathrm{IU} / \mathrm{ml}$ ). The non-template control consisting of water was consistently negative. The sensitivity limit of our assay was determined to be $765 \mathrm{IU} / \mathrm{ml}$ using the WHO International Standard for HCMV. We failed to extract RNA from 10 samples (each 10 tissues section slices) that was sufficient in both quantity and quality to perform TaqMan PCR as assessed by NanoDrop 2000 (Thermo Scientific).

To quantify HCMV immunoreactivity in CEA samples, we graded positive staining (Figure 2F-2G) as previously described [29]. HCMV immunoreactivity was either grade I or grade II. Grade I was the most prevalent for IE (43/57 or $75 \%$ ) and all LA positive samples were grade I (Figure 3D). Cells expressing HCMV antigens were mainly detected in the shoulder regions of the plaques, in areas adjacent to the necrotic core and occasionally also in the fibrous cap (Figure 2F, 2+). The cellular targets for HCMV infection was mainly macrophages/ foam cells and smooth muscle cells although we also

Table 2 TaqMan PCR analysis and cellular localization of viral antigens on selected IHC-positive or -negative for HCMV antigens

\begin{tabular}{|c|c|c|}
\hline Sample & Viral antigens localization as revealed by immunohistochemistry & TaqMan PCR (IU/ml) \\
\hline CP 03 & Endothelial cells, macrophage/foam cells, smooth muscle cells & 10,298 \\
\hline CP 05 & Endothelial cells, macrophage/foam cells, smooth muscle cells & 2,598 \\
\hline CP 30 & Endothelial cells $+/-$, macrophage/foam cells, smooth muscle cells & Undetermined \\
\hline CP 31 & Smooth muscle cells & Undetermined \\
\hline CP 36 & Macrophage/foam cells, inflammatory cells, smooth muscle cells +/- & Undetermined \\
\hline CP 37 & Endothelial cells, macrophage/foam cells, smooth muscle cells & 7,956 \\
\hline CP 44 & Endothelial cells, macrophage/foam cells, inflammatory cells, smooth muscle cells & Undetermined \\
\hline CP 47 & Macrophage/foam cells, smooth muscle cells +/- & Undetermined \\
\hline CP 101 & Macrophage/foam cells, smooth muscle cells+/- & 4,718 \\
\hline CP 08 & None detected & Undetermined \\
\hline CP 24 & None detected & Undetermined \\
\hline CP 27 & None detected & Undetermined \\
\hline CP 49 & None detected & Undetermined \\
\hline CP 51 & None detected & Undetermined \\
\hline CP 102 & None detected & Undetermined \\
\hline CP 109 & None detected & Undetermined \\
\hline CP 122 & None detected & Undetermined \\
\hline CP 123 & None detected & Undetermined \\
\hline
\end{tabular}




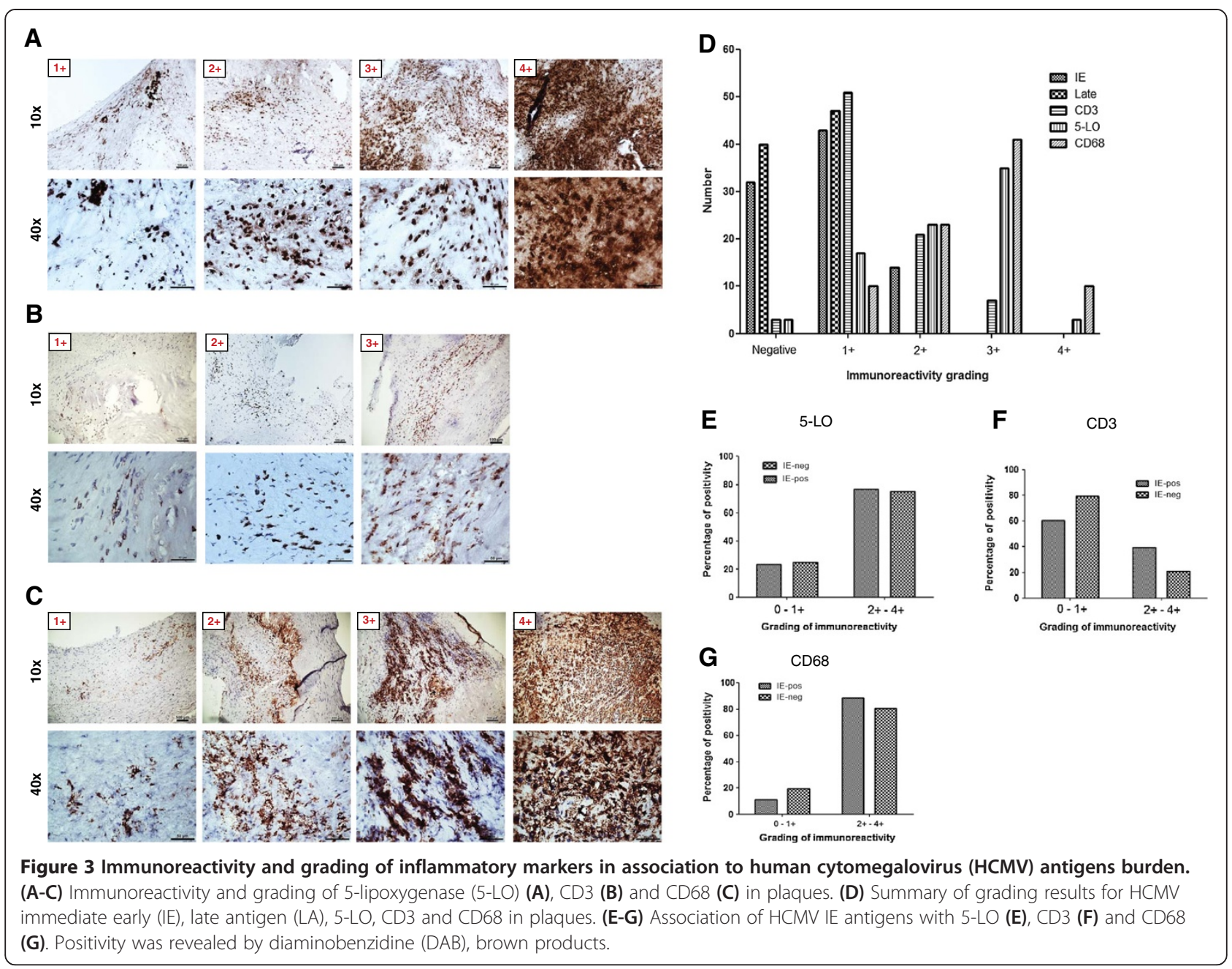

detected viral antigens in some endothelial cells and other infiltrating inflammatory cells (Figure 2B-2D and Figure 2F-2G).

To address the question whether any association exists between HCMV IgG titers and viral burden in carotid plaques, we combined the results obtained from the serology and viral IE antigens staining analyses. Among 51 patients who were positive for HCMV IE, 10 (20\%) patients had O.D. < 1 and $41(80 \%)$ patients had O.D. > 1. Among 30 HCMV IE negative patients, $6(20 \%)$ had O.D. < 1 and 25 (80\%) had O.D. > 1 (Figure 2H). Thus, we did not observe any association between viral antigen burden in the plaque and HCMV IgG levels.

\section{HCMV trended to be associated with increased inflammatory burden}

We next assessed if there was an association between HCMV infection and inflammatory markers. We stained tissue samples from CEA patients for 5-LO, CD3 and CD68; -all representing markers of inflammation. We found that $78 / 81$ (96\%), 79/82 (96\%) and 84/84 (100\%) of the CEA plaques were positive for $5-\mathrm{LO}, \mathrm{CD} 3$ and CD68, respectively (Figure $2 \mathrm{~A}$ ). We also graded these samples according to positivity (grade I-IV) as exemplified in Figure 3A-3C and summarized in Figure 3D. 5-LO proteins were abundantly expressed in macrophage/foam cells and in smooth muscle cells; 38 of $81(47 \%)$ samples were grade III or IV (Figure 3D). All examined plaques were positive for CD68 (Figure 3D); 51 of 84 (61\%) samples were grade III or IV (Figure 3D). CD3-positive cells were less abundant; 51 of $82(62 \%)$ samples were grade I, none was grade II-IV. Thus, CD68-positive macrophages and 5-LO immunoreactivity were highly abundant in atherosclerotic plaques, relative to $\mathrm{CD} 3$-positive $\mathrm{T}$ cells that were less frequently observed in CEA plaques (Figure 3D).

Next, we divided samples by the grade of HCMV IE expression and compared staining results from 5-LO, CD3 and CD68 to determine whether IE positivity was associated with a higher grade (grade II and above) of the inflammatory markers. We found no statistically significant difference in the grade of inflammatory markers between those that were low HCMV IE vs. high HCMV IE 
reactivity: IE vs. 5-LO ( $\mathrm{p}=1.0000)$; IE vs. CD68 ( $\mathrm{p}=$ $0.3408)$ and IE vs. CD3 ( $p=0.0920)$. However, we observed a trend for higher immunoreactivity among HCMV-positive plaques for CD3 and CD68 compared to that of HCMV-negative plaques (Figure 3E-3G), indicating that HCMV may be involved in driving the inflammatory process or may be associated with this process.

\section{Discussion}

We found a high prevalence of HCMV protein expression in atherosclerotic plaques, suggesting an ongoing active HCMV replication in a majority of atherosclerotic plaques. As viral antigens by their nature as foreign antigens provide targets for the immune system, it is plausible that some immune reactivity existing in the plaque is directed against HCMV peptides. This statement is supported by the fact that we found a trend for increased number macrophages and T cells in HCMV-positive plaques.

The life cycle of HCMV intrinsically involves macrophages and inflammation. HCMV maintains latency in myeloid lineage cells and becomes reactivated in macrophages differentiated by inflammatory stimuli [31]. HCMV can induce inflammation by inducing 5-LO and COX-2 expression with consequent leukotriene and prostaglandin E2 production [25,32]. Furthermore, HCMV also increases the production of pro-inflammatory cytokines, e.g. IL-1 $\beta$, IL-4, IL-6, IL-8, TNF- $\alpha$ and IFN- $\gamma$ [33]. The HCMV US28 and IE proteins induce production of IL-6 [32,34], which provides a direct link to $\mathrm{C}$-reactive protein (CRP) levels. Both IL-6 and CRP are widely used markers for systemic inflammation and predictors of coronary heart disease [35].

We detected HCMV IE DNA in $44 \%(n=9)$ of the HCMV antigen positive plaques while no HCMV IE DNA existed in HCMV antigen negative plaques $(n=9)$. In 75 arterial vascular tissues, a similar detection rate of $\mathrm{HCMV}$ DNA was reported [36]. As we found HCMV present mainly in the shoulder region and we had access to DNA from undefined parts of the plaques, it is possible that viral DNA was absent in some of the samples analyzed. Our PCR assay has a sensitivity of $765 \mathrm{IU} / \mathrm{ml}$, which is also a limiting factor. Furthermore, it is possible that some clinical HCMV strains are not detected by our assay, which is supported by our own unpublished data from cancer patients who demonstrate variability in the IE and $\mathrm{gB}$ genes sometimes resulting in lack of detection of viral genes by both our PCR assays. We also failed to retrieve RNA in sufficient quantity and quality from 10 samples to proceed with CDNA synthesis or PCR analysis. It is possible that failure to retrieve RNA was due to low amount of RNA in the necrotic core of the end-stage plaques and we were unable to determine exactly from where in the specimen the section came from. Also it is well-known that RNA is sensitive to degradation depending on storage conditions, which may also explain why we did not recover enough RNA for further analyses.

To our knowledge, only two earlier reports examined the presence of HCMV protein expression in atherosclerotic plaques with reasonably large sample cohorts [37,38]. Chiu et al. reported that 27/76 atherosclerotic plaques obtained from Canadians (35.5\%) were immunoreactive for HCMV early antigens [37], and Yi et al. detected a similar HCMV IE positivity (12/35 or $34.2 \%)$ and less expression of HCMV LA antigens (4/35 or $11.4 \%)$ in samples from Chinese Han patients [38]. We detected HCMV IE antigens in 57/89 (64\%), and LA antigens in $47 / 87$ (54\%) of atherosclerotic plaques obtained from Russian patients. The higher percentage of immunoreactivity against viral antigens observed in this cohort may be due to different sample handling; both Chiu et al. and $\mathrm{Yi}$ et al. examined formalin-fixed samples, while we used frozen samples. Detection of HCMV proteins in cancer specimens is facilitated by antigen retrieval protocols, which results in enhanced sensitivity of the assay to similar detection levels as is observed in frozen tissue sections [39]. The HCMV serostatus of $99 \%$ $(89 / 90)$ was also higher in our cohort than reported by Chiu et al. (50/76 or $65.8 \%$ ) while not examined by Yi et al. Thus, ethnic differences may exist [40] regarding the prevalence of HCMV in CEA patients.

Elevated antibody levels against HCMV was shown by others to correlate positively with atherosclerosis [12], coronary artery disease [13] and CVD mortality [5,14-16]; but a lack of correlation between HCMV antibodies in patients with CEA compared with controls, were also reported $[37,41]$. In the present study, we did not observe a significant difference between the prevalence of HCMV IgG antibodies in patients with CEA compared to controls; both groups had similar IgG prevalence. However, we did observe lower viral O.D. values in patients than controls. It is possible that the adaptive immune response to HCMV is less efficient in individuals who are at higher risk of developing atherosclerosis, or that the virus by itself provides immunosuppressive mechanisms. It is also well known that HCMV has developed multitude of sophisticated mechanisms to avoid detection by the immune system $[31,42,43]$, which may also explain the high prevalence of HCMV antigen reactivity in CEA patients, who had lower OD values than controls.

The concept of a low grade infection is in line with emerging views that there is an association between chronic low grade inflammation or infection and the slow process of arteriosclerosis [44]. HCMV induces expression of both 5-LO mRNA and proteins in addition to LTB4 production in infected smooth muscle cells [25]. Here, we detected 5-LO expression in HCMVinfected smooth muscle cells besides macrophage/foams cells, which substantiate our previous findings that 5-LO 
expression can be induced in smooth muscle cells [25] that otherwise do not express 5-LO. We observed that the proportion of 5-LO positive plaques were higher in plaques with higher HCMV antigen burden, but was not higher in HCMV positive versus negative plaques. Thus, other mechanisms than HCMV can also induce 5-LO mediated inflammation in vascular cells. High number of CD68-positive cells were associated with 5-LO expression levels (Figure 3B-3C), indicating that the main source of 5-LO was from macrophages, as was previously proposed [45]. Carotid atherosclerotic plaques containing enhanced numbers of CD3- and CD68-positive cells as indicators of increased inflammatory activity trended to be more often HCMV positive.

In summary, HCMV IE and LA antigens are abundantly expressed in carotid atherosclerotic plaques obtained from Russian patients. The seroprevalence of HCMV was very high in both Russian patients with CEA as well as in controls, but the IgG titers were significantly lower among patients than controls. There was abundant 5-LO expression and a substantial infiltration of CD68-positive macrophages in plaques, but relatively less prevalent infiltration of CD3-positive T cells. We observed a trend for increased infiltration of CD3positive $\mathrm{T}$ cells and macrophages in HCMV-positive plaques, suggesting that this virus may influence the inflammatory activity in atherosclerotic plaques.

\section{Abbreviations}

HCMV: Human cytomegalovirus; IE: Immediate early proteins;

TBS: Tris-buffered saline; CEA: Carotid endartectomy; DAB: 3, 3-diaminobenzidine; SD: Standard deviation; 5-LO: 5-lipoxygenase; SPICE: St. Petersburg Investigation of Carotid Endarterectomies; CVD: Cardiovascular disease; O.D.: Optical density.

\section{Competing interests}

The authors declare that they have no competing interests.

\section{Authors' contributions}

KCY and CSN conceived and designed the study. KCY, CT, AAM and BD performed all the experiments, analyses and generated figures. OO, ES, OR and $A K$ provided materials crucial for the study. KCY wrote the manuscript. CSN, WW, AR, LB and AA participated in the analyses and helped in drafting the manuscript. All authors have read and approved the final manuscript.

\section{Acknowledgements}

We thank Robert M. Badeau, Ph.D. for linguistic editing. This work was supported by the Swedish Heart and Lung Foundation (grant no. 20100614, 20100259), the Swedish Medical Research Foundation (K2010-56X-12615-13-3, K2012-64X-10857-19-5), CERIC (Center of Excellent for Research on Inflammation and Cardiovascular disease, Swedish Research Council, 70870302), Cardiovascular Programme and Stockholm County Council.

\section{Author details}

${ }^{1}$ Department of Medicine, Center for Molecular Medicine, CMM L8:03, Karolinska Institutet, Solna, Stockholm SE-171 76, Sweden. ${ }^{2}$ Almazov Federal Center for Heart, Blood and Endocrinology, St. Petersburg, Russia.

Received: 18 March 2013 Accepted: 4 November 2013 Published: 14 November 2013

\section{References}

1. Mocarski ES, Courcelle CT: Cytomegaloviruses and their replication. In Fields Virology, Volume 2. 4th edition. Edited by Knipe D, Howley PM. Philadelphia: Lippincott Williams and Wilkins; 2001:2629-2673.
2. Cannon MJ, Schmid DS, Hyde TB: Review of cytomegalovirus seroprevalence and demographic characteristics associated with infection. Rev Med Virol 2010, 20(4):202-213.

3. Rosenfeld ME, Campbell LA: Pathogens and atherosclerosis: update on the potential contribution of multiple infectious organisms to the pathogenesis of atherosclerosis. Thromb Haemost 2011, 106(5):858-867.

4. Epstein SE, Zhou YF, Zhu J: Infection and atherosclerosis: emerging mechanistic paradigms. Circulation 1999, 100(4):e20-e28.

5. Simanek AM, Dowd JB, Pawelec G, Melzer D, Dutta A, Aiello AE: Seropositivity to cytomegalovirus, inflammation, all-cause and cardiovascular disease-related mortality in the United States. PLoS One 2011, 6(2):e16103.

6. Joshi R, Khandelwal B, Joshi D, Gupta OP: Chlamydophila pneumoniae infection and cardiovascular disease. N Am J Med Sci 2013, 5(3):169-181.

7. Charakida M, Tousoulis D: Infections and atheromatous plaque: current therapeutic implications. Curr Pharm Des 2013, 19(9):1638-1650.

8. Streblow DN, Orloff SL, Nelson JA: Do pathogens accelerate atherosclerosis? J Nutr 2001, 131(10):2798s-2804s.

9. Popovic M, Smiljanic K, Dobutovic B, Syrovets T, Simmet T, Isenovic ER: Human cytomegalovirus infection and atherothrombosis. J Thromb Thrombolysis 2012, 33(2):160-172.

10. Melnick JL, Petrie BL, Dreesman GR, Burek J, McCollum CH, DeBakey ME: Cytomegalovirus antigen within human arterial smooth muscle cells. Lancet 1983, 2(8351):644-647.

11. Hendrix MG, Salimans MM, van Boven CP, Bruggeman CA: High prevalence of latently present cytomegalovirus in arterial walls of patients suffering from grade III atherosclerosis. Am J Pathol 1990, 136(1):23-28.

12. Blum A, Peleg A, Weinberg M: Anti-cytomegalovirus (CMV) lgG antibody titer in patients with risk factors to atherosclerosis. Clin Exp Med 2003, 3(3):157-160.

13. Blum A, Giladi M, Weinberg M, Kaplan G, Pasternack H, Laniado S, Miller H: High anti-cytomegalovirus (CMV) lgG antibody titer is associated with coronary artery disease and may predict post-coronary balloon angioplasty restenosis. Am J Cardiol 1998, 81(7):866-868.

14. Roberts ET, Haan MN, Dowd JB, Aiello AE: Cytomegalovirus antibody levels, inflammation, and mortality among elderly Latinos over 9 years of follow-up. Am J Epidemio/ 2010, 172(4):363-371.

15. Strandberg TE, Pitkala KH, Tilvis RS: Cytomegalovirus antibody level and mortality among community-dwelling older adults with stable cardiovascular disease. Jama-J Am Med Assoc 2009, 301(4):380-382.

16. Wang GC, Kao WH, Murakami P, Xue QL, Chiou RB, Detrick B, McDyer JF, Semba RD, Casolaro V, Walston JD, et al: Cytomegalovirus infection and the risk of mortality and frailty in older women: a prospective observational cohort study. Am J Epidemiol 2010, 171(10):1144-1152.

17. Cheng J, Ke Q, Jin Z, Wang H, Kocher O, Morgan JP, Zhang J, Crumpacker CS: Cytomegalovirus infection causes an increase of arterial blood pressure. PLoS Pathog 2009, 5(5):e1000427.

18. Li S, Zhu J, Zhang W, Chen Y, Zhang K, Popescu LM, Ma X, Lau WB, Rong R, $Y u X$, et al: Signature microRNA expression profile of essential hypertension and its novel link to human cytomegalovirus infection. Circulation 2011, 124(2):175-184.

19. Cour MI, Deatalaya FJL, Palau L, Contreras EF, Perezagua C: Lack of serological association between herpesvirus and atherosclerosis. Lancet 1989, 1(8632):279-279.

20. Borgia MC, Mandolini C, Barresi C, Battisti G, Carletti F, Capobianchi MR: Further evidence against the implication of active cytomegalovirus infection in vascular atherosclerotic diseases. Atherosclerosis 2001, 157(2):457-462.

21. Libby P: Inflammation in atherosclerosis. Nature 2002, 420(6917):868-874.

22. Hansson GK, Robertson AK, Soderberg-Naucler C: Inflammation and atherosclerosis. Annu Rev Pathol 2006, 1:297-329.

23. Jawien J, Korbut $\mathrm{R}$ : The current view on the role of leukotrienes in atherogenesis. J Physiol Pharmacol 2010, 61(6):647-650.

24. Radmark O, Samuelsson B: 5-lipoxygenase: regulation and possible involvement in atherosclerosis. Prostaglandins Other Lipid Mediat 2007, 83(3):162-174

25. Qiu H, Straat K, Rahbar A, Wan M, Soderberg-Naucler C, Haeggstrom JZ: Human CMV infection induces 5-lipoxygenase expression and leukotriene B4 production in vascular smooth muscle cells. J Exp Med 2008, 205(1):19-24.

26. Soderberg-Naucler C, Fish KN, Nelson JA: Reactivation of latent human cytomegalovirus by allogeneic stimulation of blood cells from healthy donors. Cell 1997, 91(1):119-126. 
27. Reeves MB, MacAry PA, Lehner PJ, Sissons JG, Sinclair JH: Latency, chromatin remodeling, and reactivation of human cytomegalovirus in the dendritic cells of healthy carriers. Proc Natl Acad Sci U S A 2005, 102(11):4140-4145.

28. Soderberg-Naucler C, Fish KN, Nelson JA: Interferon-gamma and tumor necrosis factor-alpha specifically induce formation of cytomegaloviruspermissive monocyte-derived macrophages that are refractory to the antiviral activity of these cytokines. J Clin Invest 1997, 100(12):3154-3163.

29. Baryawno N, Rahbar A, Wolmer-Solberg N, Taher C, Odeberg J, Darabi A, Khan Z, Sveinbjornsson B, FuskevAg OM, Segerstrom L, et al: Detection of human cytomegalovirus in medulloblastomas reveals a potential therapeutic target. J Clin Invest 2011, 121(10):4043-4055.

30. Dzabic M, Rahbar A, Yaiw KC, Naghibi M, Religa P, Fellstrom B, Larsson E, Soderberg-Naucler C: Intragraft cytomegalovirus protein expression is associated with reduced renal allograft survival. Clin Infect Dis 2011, 53(10):969-976.

31. Soderberg-Naucler C: Human cytomegalovirus persists in its host and attacks and avoids elimination by the immune system. Crit Rev Immunol 2006, 26(3):231-264.

32. Maussang D, Langemeijer E, Fitzsimons CP, Stigter-van Walsum M, Dijkman R, Borg MK, Slinger E, Schreiber A, Michel D, Tensen CP, et al: The human cytomegalovirus-encoded chemokine receptor US28 promotes angiogenesis and tumor formation via cyclooxygenase-2. Cancer Res 2009, 69(7):2861-2869.

33. Varani S, Rossini G, Mastroianni A, Tammik C, Frascaroli G, Landini MP, Castellani G, Soderberg-Naucler C: High TNF-alpha and IL-8 levels predict low blood dendritic cell counts in primary cytomegalovirus infection. J Clin Virol 2012, 53(4):360-363.

34. Carlquist JF, Edelman L, Bennion DW, Anderson JL: Cytomegalovirus induction of interleukin- 6 in lung fibroblasts occurs independently of active infection and involves a $\mathrm{G}$ protein and the transcription factor. NF-kappaB. J Infect Dis 1999, 179(5):1094-1100.

35. Luc G, Bard JM, Juhan-Vague I, Ferrieres J, Evans A, Amouyel P, Arveiler D, Fruchart JC, Ducimetiere P, Grp PS: C-reactive protein, interleukin-6, and fibrinogen as predictors of coronary heart disease - The PRIME study. Arteriosd Throm Vas 2003, 23(7):1255-1261.

36. Chen RZ, Xiong SD, Yang YZ, Fu WG, Wang YQ, Ge JB: The relationship between human cytomegalovirus infection and atherosclerosis development. Mol Cell Biochem 2003, 249(1-2):91-96.

37. Chiu B, Viira E, Tucker W, Fong IW: Chlamydia pneumoniae, cytomegalovirus, and herpes simplex virus in atherosclerosis of the carotid artery. Circulation 1997, 96(7):2144-2148.

38. Yi L, Wang DX, Feng ZJ: Detection of human cytomegalovirus in atherosclerotic carotid arteries in humans. J Formos Med Assoc 2008, 107(10):774-781.

39. Scheurer ME, Bondy ML, Aldape KD, Albrecht T, El-Zein R: Detection of human cytomegalovirus in different histological types of gliomas. Acta Neuropathol 2008, 116(1):79-86.

40. Inzitari D, Hachinski VC, Taylor DW, Barnett HJ: Racial differences in the anterior circulation in cerebrovascular disease. How much can be explained by risk factors? Arch Neurol 1990, 47(10):1080-1084.

41. Hagiwara N, Toyoda K, Inoue T, Shimada H, Ibayashi S, lida M, Okada Y: Lack of association between infectious burden and carotid atherosclerosis in Japanese patients. J Stroke Cerebrovasc Dis 2007, 16(4):145-152.

42. Soderberg-Naucler C: HCMV microinfections in inflammatory diseases and cancer. J Clin Virol 2008, 41(3):218-223.

43. Powers C, DeFilippis V, Malouli D, Fruh K: Cytomegalovirus immune evasion. Curr Top Microbiol Immunol 2008, 325:333-359.

44. Stollberger C, Finsterer J: Role of infectious and immune factors in coronary and cerebrovascular arteriosclerosis. Clin Diagn Lab Immunol 2002, 9(2):207-215

45. Cipollone F, Mezzetti A, Fazia ML, Cuccurullo C, lezzi A, Ucchino S, Spigonardo F, Bucci M, Cuccurullo F, Prescott SM, et al: Association between 5-lipoxygenase expression and plaque instability in humans. Arteriosd Throm Vas 2005, 25(8):1665-1670.

doi:10.1186/2042-4280-4-3

Cite this article as: Yaiw et al:: High prevalence of human

cytomegalovirus in carotid atherosclerotic plaques obtained from Russian patients undergoing carotid endarterectomy. Herpesviridae 2013 4:3.

\section{Submit your next manuscript to BioMed Central and take full advantage of:}

- Convenient online submission

- Thorough peer review

- No space constraints or color figure charges

- Immediate publication on acceptance

- Inclusion in PubMed, CAS, Scopus and Google Scholar

- Research which is freely available for redistribution 